\title{
THE RELATIVITY OF EVALUATIVE SENTENCES: DISAGREEING OVER DISAGREEMENT ${ }^{1}$
}

\author{
Justina Díaz Legaspe* \\ jdiazlegaspe@gmail.com
}

\begin{abstract}
Evaluative sentences (moral judgments, expressions of taste, epistemic modals) are relative to the speaker's standards. Lately, a phenomenon has challenged the traditional explanation of this relativity: whenever two speakers disagree over them they contradict each other without being at fault. Hence, it is thought that the correction of the assertions involved must be relative to an unprivileged standard not necessarily the speaker's. I will claim instead that so far, neither this nor any other proposal has provided an explanation of the phenomenon. I will point out several problems presented by them and I will hint to how this phenomenon could be explained by making minor adjustments to our semantic theory.
\end{abstract}

Keywords Relativism, contextualism, disagreement, semantics.

RESUMO Sentenças avaliativas (julgamentos morais, expressões de gosto, modos epistêmicos) são relativas aos padrões do falante. Recentemente, um fenômeno desafiou a explicação tradicional dessa relatividade: sempre que dois falantes discordam entre si, eles contradizem um ao outro sem estarem errados. Por isso, pensa-se que a correção das asserções envolvidas deve ser

* Profesora de Filosofia de la Universidad Nacional de La Plata / Argentina. Artigo recebido em 7/2/2012 e aprovado em 26/5/2012.

1 This paper arises from discussions carried on in the Philosophy of Language branch of the GAF group (UBA, Argentina). I therefore thank all of its members, especially to Nicolas Lo Guercio, Alfonso Losada and Ramiro Caso for comments on earlier drafts. The first draft of this paper was presented at the II Linguistics and Philosophy Colloquium, Belo Horizonte (Brazil), 2011: I am indebted with all of the audience and thankful for all their useful comments.

KRITERION, Belo Horizonte, $n^{\circ}$ 127, Jun./2013, p. 211-226 
relacionada a um padrão desprovido de privilégio e não necessariamente ao padrão do falante. Eu sustentarei, ao contrário, que até agora nem esta nem alguma outra proposta forneceu uma explicação do fenômeno. Eu assinalarei diversos problemas apresentados por essas propostas e sugerirei o modo como este fenômeno poderia ser explicado ao fazer pequenos ajustes em nossa teoria semântica.

Palavras-chave Relativismo, contextualismo, desacordo, semântica.

It is no secret that the truth value of some of our everyday sentences can be relative somehow: sentences containing indexicals, for instance, vary their truth conditions alongside with the variation of the values of certain parameters in the context of utterance. ${ }^{2}$ But this is not the only way in which sentential truth value can vary. Recently a fair amount of attention has been devoted to the truth-relativity of what I will call "evaluative judgments": 3 the truth value of moral judgments, sentences containing predicates of taste or epistemic modals and even sentences about the future seems to vary relatively to the value of certain parameters associated to the speaker -for instance, the evaluative standards she is committed to in the case of sentences containing taste predicates-. Thus, "Feijoada is delicious" will be true if I assert it but it may be false if you utter it, because under my evaluative standard for food taste feijoada ranks high, while under yours it classifies as non-tasty. In other words, the same sentence will differ in truth value when asserted in different contexts of utterance and assessed in different circumstances of evaluation.

Our current double-index semantic theories ${ }^{4}$ have plenty of resources to explain this truth-relativity perfectly well. However, in the last years a problem

2 In what follows I will use the concept of context used in double index semantic theory (see Lewis 1998, Kaplan 1977, 1989)): according to it, the context of utterance is the index constituted by parameters corresponding to agent or speaker, time and location of the utterance and possible world of the utterance. I will also refer to the circumstances of evaluation, different from the context of utterance but also an index containing at least one parameter (a possible world). While the context of utterance helps determining the semantic content expressed by the sentence, the circumstances of evaluation determine the sentence's truth value. In most cases, the values provided for the parameters in both index are those in the context of utterance. In both cases sui generis parameters can be added if needed (as happens in the case I will be considering in the paper). Note that contexts of utterance and circumstances of evaluation differ from what MacFarlane calls "contexts of assessment" or "perspectives", constituted by a possible world and a certain evaluative parameter (say, a standard of taste) which is not necessarily that of the speaker. This context or perspective is used for assessing the correctness of assertions of evaluative sentences. The difference between the three of them is significant for the aim of this paper and should be in sight.

4 I am referring to Kaplan-style semantic theories. See Kaplan $(1977,1989)$ or Lewis $(1998)$. 
has been detected that could motivate the modification of some traits of these theories in order to fully explain the use pattern of this kind of sentences. The problem emerges whenever two speakers disagree over them: intuitively we would say that the two sentences involved ("Feijoada is delicious", "No, it is not") contradict each other or are mutually inconsistent -hence, there is a disagreement-. But, due to the truth-relativity of these sentences, both utterances appear to be expressing something true and consequently neither speaker can be accused of being at fault -hence, there is a faultless disagreement-. How can we explain this phenomenon?

A close study of the case of faultless disagreements has led to the idea that the correction or accuracy of the speech acts involving these sentences must be relative to a parameter -such as an evaluative standard- whose value is not necessarily linked to the speaker. In other words, even when the context of utterance provides a certain value to this sui generis parameter, in order to account for faultless disagreements we have to provide a different value for this parameter. Thus, even when in each context of utterance and in its associated proper circumstances of evaluation each of the uttered sentences is true, the fact that they constitute a disagreement can be explained pointing at the fact that, from a single context (not necessarily that of any of the speakers) only one of the sentences is true and the other is false. This forces the appeal to a new context different to the context of utterance- the context of assessment or perspective-, constituted by the evaluative parameter with a value which is not necessarily that of any of the speakers, but that of the assessor. But is this really how it goes? In what follows I will claim that so far, none of the current theories on the topic has managed to provide a real solution to this problem, not even the radical relativism that proposed this modification. To explain why, I will point out several problems presented by each of these theories. At the end, I will provide some hint of how this problem could be solved and why, in order to do so, double-index semantics must be altered, even if not in the way suggested by radical relativism.

\section{Relativity of truth and faultless disagreements}

Standard semantic theories for languages with context-sensitive expressions ${ }^{5}$ can account nicely for truth value relativity appealing either to locating the relevant parameters within the context of utterance or to locating them within the circumstances of evaluation (see note 2 ). The truth value of

5 Kaplan, (1977, 1989), Stalnaker (2007) and Lewis (1998) provide different variations of this theory. 
certain sentences like those containing taste predicates, epistemic modals and moral judgments (let's call them "evaluative judgments" even when not all of them depend on an evaluative parameter $)^{6}$ is relative to the value of a certain sui generis parameter; taking the case of taste predicates as a toy example, the truth value of the sentence containing them will be relative to the value of the evaluative taste standard held by the speaker. This relativity can be thus explained either by locating this standard as a contextual parameter (as proposed by indexical contextualism $)^{7}$ or as a parameter in the circumstances of evaluation (as non-indexical contextualism suggests). ${ }^{8}$ In the first case, the semantic content of the sentence is taken to contain hidden indexicals saturated by the value of the relevant parameter within the context of utterance or they are taken to express a schematic semantic content that gets enriched by adding to it the value of the standard parameter as a non-articulated constituent. In both cases, the semantic content of the sentence or what it says is something in the line of "Feijoada is delicious for me". In the case of non-indexical contextualism, the parameter does not enter into the context of utterance but is located instead within the circumstances of evaluation. In that case, the semantic content of the sentence is just "Feijoada is delicious", and its true value depends on the value given to the parameter, which is determined by the speaker in the context of utterance. ${ }^{9}$

The resulting truth-relativity appears also in the dimension of linguistic behavior: the assertions ${ }^{10}$ of these sentences are intentional acts governed by norms. Among them, probably the most relevant -at least to our purposesis "the norm of truth", which relates the semantic concept of truth to the pragmatic concept of correctness of assertions. Its natural form ("assert P only if $\mathrm{P}$ is true") can be modified to take into account the aforementioned truth value relativity of evaluative sentences: ${ }^{11}$

6 The truth value of sentences with epistemic modals depends on the amount of evidence of the agent and, following Stanley (2007), certain traits of the context.

7 See López de Sá $(2007,2008)$.

8 See Lasersohn (2005), García-Carpintero (2008), Recanati $(2007,2008)$.

9 Kaplan (1977) distinguishes between proper and improper circumstances of evaluation: while proper circumstances are constituted by parameters (usually, only the possible world, but in this particular case, the possible world plus the evaluative parameter) whose values are exactly those given to those parameters in the context of utterance (hence, the actual world and the taste standard of the speaker), improper circumstances can give different values to these parameters. In the cases under study, nothing allows the construal of the circumstances as improper and therefore, the values given to the parameters will be those of the context of utterance.

10 By "assertion" here we will be referring only to the speech act of affirming a particular content or its negation.

11 Kölbel (2009). 
The utterance of an evaluative sentence $s$ by a speaker $S$ in a context $C$ will be considered correct only if the content sexpresses in $C$ is true at the world of $C$ and under the evaluative standard held by $S .^{12}$

Thus, we can account for the truth-relativity of these sentences and also for the correctness-relativity of their assertion to the parameter of the evaluative standard of the speaker. So what is the big deal about these sentences, then?

The problem arises with faultless disagreements, disagreements over evaluative judgments. According to MacFarlane, ${ }^{13}$ only a radical relativist perspective can account for them. In order to judge whether this is true we should pause and reflect, first, over the nature of the problem and second, over what is needed to solve it.

Faultless disagreements are, first of all, disagreements. For them to exist two assertions are needed, one affirming the content and one negating it. If the sentences uttered in those assertions express two different contents instead of one content and its negation, the resulting exchange won't classify as a disagreement but as a misunderstanding. ${ }^{14}$ On top of that, the disagreement has to be faultless. That is, both assertions are to be construed as correct under the standard of each speaker. Thus, even when both assertions are correct in that sense, it is still the case that they are incompatible assertions, speech acts expressing thoughts that could not be entertained by the same speaker at the same moment. This is due to the fact that, assessed from only one context of assessment, only one of the assertions can count as correct. Thus, the faultless part of these disagreements is based on the fact that each assertion is correct (according to its speaker's standards, that is, when its truth value is evaluated in the proper circumstances of evaluation corresponding to the context of utterance) while the disagreement part answers to the incompatibility of both assertions, the impossibility of both speech acts being correct under one single standard. In order to account for a faultless disagreement we need, then, at least two different values to the relevant parameter or evaluative standard in play:

12 In what follows I will be assuming a close link between this norm of truth and correctness as an aim of assertion, the former clarifying the latter.

13 MacFarlane (in progress).

14 Consider, for example, a conversation that takes place between two speakers located in different cities: "Leire: It rains a lot. / Sebastián: No, it doesn't." At first sight, the exchange looks as if it were a disagreement over the occurrence of rain in the place where the conversation takes place. If that were the case, we would be facing a faulty disagreement, one in which one of the speakers would be mistaken. But if, as said, the two speakers are located in different cities (Leire in Madrid, Sebastián in Buenos Aires), the appearance is based on a mistake: what Leire is actually saying is that it rains a lot in Madrid, while Sebastián is claiming that it isn't raining in Buenos Aires. The expressed contents are different, and the discussion occurs only because Sebastián misunderstands Leire as saying that it rains where he is located. If we look for a disagreement we need one single content affirmed and denied in two different speech acts. 
Alfonso: Feijoada is delicious. (true under Alfonso's standard) (true under standard X) Nicolás: Feijoada is not delicious at all! (true under Nicolás' standard) (false under standard X)

Only with that many standards we can account for faultless disagreements: even when Nicolás' and Alfonso's assertions are true under their own standards (hence, faultlessness), both of them are inconsistent or contradictory under standard X (hence, disagreement).

Is that all there is to faultless disagreements? No. Besides this, a theory willing to account for the phenomenon must provide an explanation for its pragmatic dimension, the actual practice of faultlessly disagreeing. In this sense, we are facing the state in which two speakers happen to be when each of them contends what is said by the other. Now, in some sense, there cannot be such a thing as faultlessly disagreeing (launching a discussion over something while admitting, at the same time, that the contender is right and not at fault). Every time we engage in a discussion over an evaluative judgment we do it because we think we are right and our contender is wrong, and even when we know that she is right under her own standards, we intuitively take her to have committed some kind of fault. ${ }^{15}$ Since evaluative judgments are standardrelative, we should understand that our contender is actually asserting correctly. But alas, she is correct under her own standards but not under ours. It is this assessment of the other speaker's claim under our own standard what prompts us to discuss. Hence disagreements, in practice, are faulty because they are centered: for each of us, we are the measure of all evaluative things. When the moment comes to face an evaluative disagreement we will discuss it as if its truth could be settled down objectively.

Thus, any theory willing to account for faultless disagreement must provide an answer to two different questions: how is it possible for an evaluative sentence to be assessed as correct (from the speaker's perspective) and at the same time as incorrect (from the assessor's perspective)? And why is it that speakers behave as if they were facing an objective disagreement whenever they discuss over subjectively relative sentences like these? In order to answer both questions, all of these requirements have to be fulfilled:

a. Sameness of content

15 We can either take it that our contender shares our standard but she is misapplying it (ascribing a first order fault to her) or acknowledge that her standard differs from ours, and even so consider that she is wrong in not being committed to our own standard but to a different one (ascribing to her a second order fault). 
b. Incompatible and, at the same time, faultless speech acts (at least two evaluative standards in play)

c. Centered disagreements: the speaker must feel the urge to challenge what the other contender just said because it is wrong under her standards

Now that we know what a theory accounting for faultless disagreements in their two dimensions should give us, let's look at what the theories at stake do give us.

\section{Some closed roads}

Since MacFarlane's challenge, many philosophers have been deeply concerned with the problems raised by faultless disagreement. Not dealing with them properly would be a sign of the inadequacy of traditional semantic theories for accounting for the use of truth-relative sentences. Now, as we shall see, it is difficult for contextualism, either indexical or non-indexical, to comply with all (a), (b) and (c) above and therefore to provide an answer to both questions regarding faultless disagreements.

One way of solving the problems related to faultless disagreement is, naturally, by denying its relevance. ${ }^{16}$ Indexical contextualism does exactly that, and it does it at the cost of not satisfying (a) by locating the evaluative standard within the context of utterance and, thus, within the semantic content expressed by the sentence. According to López de Sá, ${ }^{17}$ an advocate of this alternative, evaluative judgments contain hidden indexicals which make evaluative sentences of the form of " $\mathrm{X}$ is $\mathrm{P}$ " equal in content ${ }^{18}$ to " $\mathrm{X}$ is $\mathrm{P}$ according to my standards for P-ness". ${ }^{19}$ This move dissolves the theoretical import of the problem: with no single content affirmed and denied in the sentences in the discussion we don't really have a disagreement at sight and, hence, no faultless disagreement. However, if competent speakers are usually aware of all the constituents of the content ${ }^{20}$ and they recognize the difference in the evaluative standards held by each speaker, why do they feel the urge to discuss? According to López de Sá this is due to the fact that evaluative expressions trigger a presupposition of commonality that leads the speaker

16 Stojanovic (2008) and lacona (2008) also opt for such a denial.

17 López de Sá $(2007,2008)$.

18 According to Kölbel's presentation of indexical contextualism, both sentences express the same contents (2004) or are propositionally equivalent (2007). I would add, though, that there are conversational differences between them, since one of them seems more felicitous in contexts in which the other is not so. See Kölbel (2007).

19 Even if it is not without importance, the discussion over individual or communal standards won't affect the main point either so I won't dwell on it.

20 See Orlando (2011). 
to assume that her contender's evaluative standard is the same than hers: what follows naturally is that her contender is at fault (she has misapplied the common standard) and has to be corrected. In López de Sá's own terms, even if this fails to explain what he calls Contradiction (that in any conceivable conversation whatsoever, it is indeed the case that utterances of (say) " $a$ is good" and " $a$ is not good" would contradict each other), it manages to explain what he calls Genuine Disagreement (that in these conversations it is common ground that utterances of (say) " $a$ is good" and " $a$ is not good" contradict each other). ${ }^{21}$ According to López de Sá this is all it takes to solve the riddle of faultless disagreements. In actual linguistic usage all we have is Genuine Disagreements, while "there is no pressure to acknowledge that the alleged "facts" stated in Contradiction are indeed real." $(2007,275)$

Smart move, but not without problems. Claiming that an evaluative sentence contains, as part of its content, an evaluative standard leads to two unwanted consequences. First, the distortion of topic: ${ }^{22}$ intuitively, we would say that these discussions are over the content of the evaluative judgment and not, as this seems to show, over each speaker's evaluative standards. Second, the impossibility of accounting for these discussions in terms of disagreements but only in terms of misunderstandings: it is pretty clear that it is not entirely rational to discuss the preferences of our contenders. The discussion comes from mistaking a subjective use of the evaluative predicate as an objective one. ${ }^{23}$ Now, ascribing a systematic misunderstanding to the speaker's community seems a bit too much. Speakers feel they know what they are doing when they launch these discussions and this should be respected. ${ }^{24}$

Therefore, indexical contextualism doesn't manage to provide a satisfactory account of the phenomenon. Sadly, non-indexical contextualism doesn't fare any better. Even though it satisfies requirements (a) and (c), it fails to comply with requirement (b). In this case, the evaluative standard is located in the circumstances of evaluation instead of being located in the context of

21 López de Sá $(2007,275)$. My italics.

22 Kölbel (2008a).

23 lacona (2008) claims that there is an ambivalence between objective and subjective uses of evaluative predicates. Subjective uses are those by means of which the speaker wants to convey something like "I like dulce de leche ice cream" and won't allow sensible uses of "Feijoada is delicious but I don't like it" Objective uses, in turn, allow a sensible use of this sentence.

24 Some authors have claimed that speakers are semantically blind regarding the semantics of words like "know" which work in a similar way as taste predicates. Why, then, should speakers have a better grasp of these last expressions? To this objection it could be argued that, although they follow a similar pattern (the truth values of sentences containing them are all relative to the value given to a certain sui generis parameter), not all the "evaluative predicates" behave exactly in the same way. The difference between the semantic blindness associated to "know" and its absence in the case of, say, "tasty", could be presented as one of these divergences. I thank the anonymous referee of Kriterion for this observation. 
utterance: this avoids having the value of the relevant parameter (say, the evaluative standard) within the semantic content. Recall that according to double index semantics, the context in which the truth value of the content of sentences is assessed is construed as an index constituted by a number of parameters (usually world, agent, time and location). ${ }^{25}$ In order to explain the truth-relativity of evaluative sentences, a sui generis parameter is added to this index (say, the parameter corresponding to a standard of taste). Now, according to Kaplan, the values of these parameters are fixed by the context of utterance: even if the parameter is located within the circumstances of evaluation, it takes its value from the speaker in the context of utterance. This is to be expected in the case of evaluative judgments, since intuitively the assertion of an evaluative sentence is correct if it expresses a true proposition according to the value of the evaluative standard held by the speaker (that is: "Feijoada is tasty" will be true, uttered by you, if you happen to consider feijoada tasty). But this prevents us from assessing any assertion from any standard different from that of its utterer: since the relevant value is always that of the speaker, an assertion cannot be assessed as incorrect if it is true under the standard of the speaker (that is, I wouldn't be able to assess your utterance of "Feijoada is tasty" as incorrect, even if it is not tasty for me, if you happen to like Feijoada). ${ }^{26}$ As a consequence, this perspective cannot explain disagreements (which launch whenever a speaker assesses as incorrect her contender's assertion). In other words, it cannot comply with (b) above, which demands at least two different standards in play.

Despite the struggle of these theoretical perspectives, the main answer continues to be that of MacFarlane's radical relativism. ${ }^{27}$ According to it, the assertion of an evaluative sentence can get a deontic value (accurate/inaccurate, correct/incorrect) when it is assessed against any standard, not necessarily that of the speaker, located in a context of assessment or perspective, different to the context of utterance and the associated circumstances of evaluation. To emphasize it: non-indexical contextualism is silent on the issue of the assessment-relativity of assertion's correction, ${ }^{28}$ but if it wasn't, it should claim that an assertion is correct relative to the speaker's standards. In contrast,

25 Lewis (1998).

26 It should be taken into account at this point that sentences with taste predicates are toy examples here. Of course I wouldn't assess your utterance of "Feijoada is tasty" as incorrect (especially because this sentence usually appeals to a subjective use of the predicate. See lacona, (2008)), but maybe I would like to assess as incorrect your assertion of "Beating animals is morally correct" if it comes out as false under my moral system of norms, even if it comes as true under your own moral system of norms.

27 MacFarlane $(2007,2008)$ and Kölbel (2008b).

28 García Carpintero (2008). 
for radical relativism the assertion of an evaluative sentence will be correct or incorrect according to any standard whatsoever: there is no privileged standard for assessment: "what makes a view "relativist" is its relativization of the notion of accuracy to contexts of assessments." (MacFarlane, 2007, 27).

Instead of classifying assertions as "correct" or "incorrect", MacFarlane calls them "accurate" or "inaccurate". ${ }^{29}$ The concept of accuracy, by definition, is based on the potential truth value that the asserted sentence would have assessed in contexts other than (although not necessarily) the circumstances of evaluation:

Perspectival Accuracy: An acceptance (rejection) of a proposition $\mathrm{p}$ at a context $\mathrm{C}_{\mathrm{U}}$ is accurate (as assessed from the context $\mathrm{C}_{\mathrm{A}}$ ) iff $\mathrm{p}$ is true (false) at the circumstance $\left\langle\mathrm{WC}_{\mathrm{U}}, \mathrm{SC}_{\mathrm{A}}\right\rangle$, where $\mathrm{WC}_{\mathrm{U}}=$ the world $\mathrm{pf}_{\mathrm{U}}$ and $\mathrm{SC}_{\mathrm{A}}=$ the standard taste of the assessor at $\mathrm{C}_{\mathrm{A}} \cdot(2007,26)$

With this tool in hand, MacFarlane provides a nice answer to the problem, for, contrary to what happens in non-indexical contextualism, the assertion of an evaluative sentence can get two different deontic values at the same time: even if it is correct when assessed under the speaker's standard, it can be incorrect when assessed under the assessor's perspective (that is: your utterance of "Feijoada is tasty" is correct according to your taste standards but it is incorrect according to mine). This satisfies point (b) above, and we take it that (a) is covered too. But, as with contextualism, there is an Achilles heel for relativism too, and it is related to the choice of an unprivileged standard as constituent of the assessment perspective.

Remember that, in order to explain both dimensions of faultless disagreement, the theory should account for the fact that speakers behave, in engaging these discussions, as if they were objective discussions. As (c) claims, what is needed then is to center the disagreeing in the speaker's standard. Translated to MacFarlane's lingo, (c) could be rephrased as this:

c'. Centered disagreements: the speaker must be moved to challenge what the other contender just said because it is inaccurate under her standards

In MacFarlane's perspective, this means that the assessor launches a discussion whenever she acknowledges the inaccuracy of the speaker's assertion under her own standard (I would defy your utterance of "Feijoada is tasty" if I assess it as incorrect under my own perspective, disregarding how it comes out under 
yours). And apparently MacFarlane can explain precisely this: "one is entitled to challenge an assertion when one has good grounds for thinking that the assertion was not accurate (relative to the context of assessment one occupies in issuing the challenge), and a successful response to such a challenge consists in a demonstration that the assertion was, in fact, accurate (relative to the context of assessment one occupies in giving the response)" (2007, 28-29). ${ }^{30}$ This explains why it is that, in disagreeing over evaluative judgments, speakers act as they do when facing an objective disagreement: disagreements seem to be centered.

But a closer look at MacFarlane's concept of accuracy shows that this move is, at least, dubious. Remember that an assertion is accurate whenever it is true in a certain perspective or context of assessment independent from that of the speaker, containing an unprivileged standard. This means that nothing anchors the standard used for the assessment to the utterer of the assessed sentence. And this becomes a problem because, if things are so, the speaker won't know how to comply with the norm of assertion. If there is no privileged perspective or context of assessment then we cannot aim to assert accurately.

This argument was presented by Evans ${ }^{31}$ against temporal relativism, and it was used against MacFarlane's radical relativism by García-Carpintero ${ }^{32}$ among others. ${ }^{33}$ According to García-Carpintero, radical relativism doesn't give us solid reasons for abandoning our intuitions about intentional acts like assertion and correctness as an attainable goal. MacFarlane, in turn, acknowledges that accuracy should work as an aim of assertion ${ }^{34}$ and answers that "when we are talking about achieving aims, there is a privileged context of assessment that matters in a way that others don't -the one occupied by the person who has those aims." (2007, 27, his italics). Thus, whenever a speaker asserts some sentence, her aim is always to assert a true (accurate) one according to her own standards. Problem solved.

Or is it? Evaluative standards seem to be playing here two different roles:

(1) assessing the correctness of our own assertions (making correctness an attainable aim of assertion), and

(2) assessing the correctness of assertions performed by any speaker

30 Following Brandom, 1994.

31 Evans, G. Does Temporal Logic Rest on a Mistake? In Evans (1985).

32 García-Carpintero (2008), who embraces a moderate relativisms instead.

33 It has also been used against other kind of relativisms, for example by Egan, Hawthorne and Weatherson (2005).

34 "Accuracy as aim: We aim for our speech acts and mental states to be accurate. When they are not accurate, they have, in a certain sense, 'misfired'." $(2007,27)$. 
Radical relativism posits unprivileged standards in the role of (2): fixing standards to speakers in this role of assessment would ban the theory from explaining faultless disagreements, as happens with non-indexical contextualism. But the move MacFarlane seems to be doing here is to privilege the speaker's standard in the role of (1), in order to gain accuracy as an aim of assertion. And this seems a bit tricky: this move, to relativize accuracy to any unprivileged standard in (2) and to unrelativize it, anchoring it to a privileged standard in (1), has an ad hoc flavor. Now, the radical relativist needs to decide whether he wants to privilege the speaker's standard for both roles or if he prefers not to privilege it in any of them. If he chooses the latter, he loses accuracy as aim of assertions and cannot account for (c). If he chooses the former, it is unclear why it is different from a non-indexical contextualism, and thus he faces the same problems this perspective has. Either way, radical relativism doesn't succeed in explaining faultless disagreements comprehensively.

\section{Centered disagreement and a way out}

In order to solve the problem of faultless disagreements we have to comply with requirements (a), (b) and (c); in terms of the roles of evaluative standards presented above, this implies positing the speaker's standard in role (1) (in order to have faultless disagreements and correctness as an aim of assertion) and, somehow, positing it also in role (2) whenever the speaker plays the role of assessor of the utterance of others, (in order to center the disagreement and explain the practice of disagreeing); usually, any discussion between two speakers will have both of them fulfilling the role of utterer and also the role of assessor of the utterances of the other speaker. Now, none of the theories involved have managed to satisfy all the three requirements (a) to (c). Indexical contextualism refuses to satisfy (a) and loses the chance of giving an appropriate account of what intuitively is the topic of these discussions. Non-indexical contextualism, by making the speaker's standard play both roles, loses the chance of satisfying (b). Finally, radical relativism puts an unprivileged standard in charge of determining both roles. But then, correctness ceases to be an appropriate goal for assertion and, at the same time, locating the speaker's standard as privileged in the role of determining correctness for assertions (role (1)) makes the theory indistinguishable from non-indexical contextualism.

What should we do, then? We must look for a theory that complies with each point by (a) not locating the evaluative standard within the semantic 
content, (b) providing a standard for fulfilling role (1) and a different one for role (2) and (c) centering this last standard in the speaker-now assessor of other's utterances-. The core of the problem lies in which standard should determine the correctness of assertions when satisfying role (1). If it is the speaker's standard, then correctness can be the aim of assertion but we lose the chance of explaining faultless disagreement and (b) is not satisfied. But, if it is an unprivileged standard, correctness as an aim for assertion would be lost completely. Satisfying all the requirements seems as an impossible task for a theory, but surprisingly it is not so.

One way of achieving this is by adjusting some technicalities of standard double-index semantic theories. Remember that, according to them, only the presence of an operator justifies switching the value of a certain parameter in the circumstances of evaluation from that corresponding to the context of utterance to a different one. This prevents assessing the correctness of a sentence by any other standard different than the speaker's -since no operator is linked to taste predicates-. Unless, of course, the context of utterance is expanded so as to incorporate not just a single speaker but several: all the speakers taking part in the dialogue. ${ }^{35}$ Even though, in this case, the speaker's is not necessarily the standard determining correctness, assertions can still aim to be correct. All the speaker has to do is to aim to assert something correct under his standard and/or under his contender's. But it is questionable whether this solution gets things right: whenever a speaker discusses over an evaluative judgment it doesn't seem to aim to assert something correct under her contender's standard, especially when she assumes that her contender is wrong. What she seems to do is to assert what turns out to be correct under her own standard.

Instead, we can leave the speaker's standard fulfill role (1) but centering the standard fulfilling role (2) fixing it to the speaker's perspective: the speaker's perspective becomes relevant for measuring both the correctness of her own assertions and the correctness of others as well. This is different from choosing an unprivileged standard for fulfilling this role, but it is also different from fixing both roles to the speaker's standard. This move constitutes a subtle but helpful middle way between these options. Centering the standard means, approximately, what MacFarlane was gesturing at above: it is the speaker's standard the one that should determine the correctness of his assertions (role (1)), but also, the one used for the assessment of any other assertions made to allow the assessment of each proposition under all relevant standards. 
by other's (role (2)). Thus, this last role is not fulfilled by an unprivileged standard, but from the perspective of a contender in the disagreement, who asserts something in it and assess what the other's claim by means of the same standard: hers.

In order to understand what would be the difference between this proposal and non-indexical contextualism, let's examine the issue more closely. Recall that, according to MacFarlane, one is entitled to challenge an assertion when one has good grounds for thinking that the assertion was not accurate under the perspective one occupies in issuing the challenge. This explains why it is that when disagreeing over evaluative judgments, speakers act as they do when facing an objective disagreement: these disagreements are centered, for each speaker assesses the accuracy of her contender's assertions from her own perspective. Thus, even if the speaker understands that the contender has asserted a content that is accurate from his standards, she feels the urge to challenge it if it comes out as inaccurate under her own. This is very different from what is expected from a non-contextualist theory, from which each speaker's claim can only be assessed as correct or incorrect from his or her own standards. But it is also different from MacFarlane's own radical relativism, according to which the role of (2) is satisfied by an unprivileged standard whatsoever. So what is the difference, then, between this proposal and non-indexical contextualism? For non-indexical contextualism, the speaker must assert what is correct under her own standards and each assertion must be assessed under its utterer's standard. In our proposal, the speaker must assert what is correct under her own standards, but in order to assess any other assertion she can appeal to her own standards and not to those of the speaker. And what is the difference between this proposal and radical relativism? According to the latter, the accuracy of an assertion can be measured by any standard whatsoever in any of its roles. In our proposal, (1) is fulfilled by the speaker's standard and each contender in the discussion uses her own standard to assess everyone else's assertions. We get two different standards but we attain a centered disagreement that can account for (a), (b) and also for (c).

In a nutshell: a way out towards a correct explanation of every dimension in the problems raised by faultless disagreements is to build an alternative position based in centering the standard in the speaker: the same standard she used for assert an evaluative sentence will be used to measure the correctness of every utterance asserted in the discussion, disregarding who the speaker is and what her standards are. Recall that evaluative standards play the two mentioned roles: determining the correctness of my own assertions and assessing the correctness of other assertions. Now, they operate in a different way in each 
of the roles. When it is relevant to determine to assess the correctness of what I asserted in order to allow myself to comply with the norm of assertion (role (1)), the relevant standard will be the one I am committed with. But my standard will be used not only to assess the correctness of my own assertions but also to assess the correctness of every other evaluative judgment that I could face (role (2)). That is what it means for the standard to be centered.

\section{Conclusion}

The problem of faultless disagreements appears to have no clear solution other than radical relativism. But, as we saw, the problem is even much more complex than expected since it involves a series of requirements which must be obtained in order to reach a satisfactory explanation. Now, most of the theories in charge of solving this puzzle cannot satisfy all of these requirements for some reason or other. This does not mean that the problem is unsolvable, though: it only means that, in order to solve it, we have to modify slightly certain traits of standard semantics, allowing each speaker to center his dealings with the usage of evaluative expressions (hers of other's) in his own standard. Only in this way we can have a theory complying with every requisite needed for solving the problem. That is, then, the road in front of us.

\section{Bibliographic references}

BRANDOM, R. - Making It Explicit. Cambridge: Harvard University Press, 1994. EGAN, A. / HAWTHORNE, J. / WEATHERSON, B. - "Epistemic Modals in Context", In: PREYER, G. / PETER, G. (eds.), Contextualism in Philosophy. Oxford: Oxford University Press, 2005. p. 131-68.

EVANS, G. - Collected Papers. Oxford: Clarendon Press, 1985. p. 343-363.

GARCÍA-CARPINTERO, M. - "Relativism, Vagueness and What is Said", In: GARCIA-CARPINTERO, M. / KÖLBEL, M. (Eds.), Relative Truth. New York: Oxford University Press, 2008. p. 129-156.

GARCIA-CARPINTERO, M. / KÖLBEL, M. (Eds.), Relative Truth. New York: Oxford University Press, 2008.

IACONA, A. - "Faultless or Disagreement", In: GARCIA-CARPINTERO, M. / KÖLBEL, M. (Eds.). Relative Truth. (297-310). New York: Oxford University Press, 2008. p. 287-296.

KAPLAN, D. (1977) - “Demonstratives”, In: ALMOG, J. / PERRY, J. / WETTSTEIN, H. (Eds.), Themes from Kaplan. New York: Oxford University Press, 1989. p. 481-564. KAPLAN, D. - "Afterthoughts", In: ALMOG, J. / PERRY, J. / WETTSTEIN, H. (Eds.), Themes from Kaplan. New York: Oxford University Press, 1989. p. 565-614. 
KÖLBEL, M. - "How to Spell Out Genuine Relativism and How to Defend Indexical Relativism", International Journal of Philosophical Studies, Vol. 15, No. 2, p. 281288, 2007.

KÖLBEL, M. - "Indexical Relativism versus Genuine Relativism”, International Journal of Philosophical Studies, Vol. 12, No. 3, p. 297-313, 2008 a.

KÖLBEL, M. - "Truth in Semantics", Midwest Studies in Philosophy, XXXII, p- 24257, 2008b.

KÖLBEL, M. - "The Evidence for Relativism”, Synthese, Vol. 166, No. 2, .p 375395, 2009.

LASERSOHN, P. - "Context Dependence, Disagreement, and Predicates of Personal Taste", Linguistics and Philosophy, Vol. 28, p. 643-686, 2005.

LEWIS, D. - "Index, Context and Content", In: LEWIS, D. - Papers in Philosophical Logic. Cambridge: Cambridge University Press, 1998. p. 21-44.

LOPEZ DE SÁ, D. - "Presuppositions of Commonality: An Indexical Relativist Account of Disagreement", In: GARCIA-CARPINTERO, M. / KÖLBEL, M. (Eds.), Relative Truth. New York: Oxford University Press, 2008.

LOPEZ DE SÁ, D. - "The Many Relativisms and the Question of Disagreement", International Journal of Philosophical Studies, Vol. 15, No. 2, p. 269-279, 2007. p. 297-310.

LOSADA, A. - To Disagree or Not To Disagree. Variations on Non-Indexical Contextualism. Unpublished. 2011

ORLANDO, E. - Disagreement and Relative Truth. Unpublished. 2011.

MACFARLANE, J. - "Relativism and Disagreement", Philosophical Studies. Vol. 132, p. 17-31, 2007.

MACFARLANE, J. - "Truth in the Garden of Forking Paths", In: GARCIACARPINTERO, M. / KÖLBEL, M. (Eds.), Relative Truth. New York: Oxford University Press, 2008. p. 81-102.

MACFARLANE, J. (in progress) - Assessment Sensitivity: Relative Truth and Its Applications. http://johnmacfarlane.net/books.html

NINAN, D. - "De Se Attitudes: Ascription and Communication", Philosophy Compass. Vol. 5, No. 7, p. 551-567, 2010.

RECANATI, F. - Perspectival Thought. A Plea for (Moderate) Relativism. New York: Oxford University Press, 2007.

RECANATI, F. - "Moderate Relativism", In: GARCIA-CARPINTERO, M. / KÖLBEL, M. (Eds.), Relative Truth. New York: Oxford University Press, 2008. p. 41-62.

STALNAKER, R. - "Pragmatics", Synthese, vol. 22, p. 272-289, 2007.

STANLEY, J. - Knowledge and Practical Interests. Oxford: Clarendon Press, 2007. STOJANOVIC, I. - What Is Said. An Inquiry Into Reference, Meaning and Content. Saarbrücken: VDM Verlag, 2008. 